C.

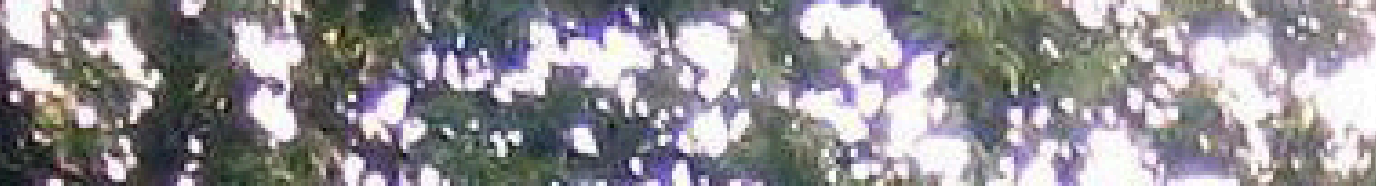
3.

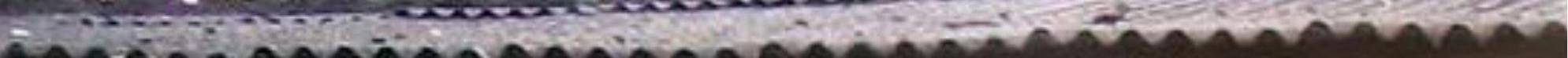
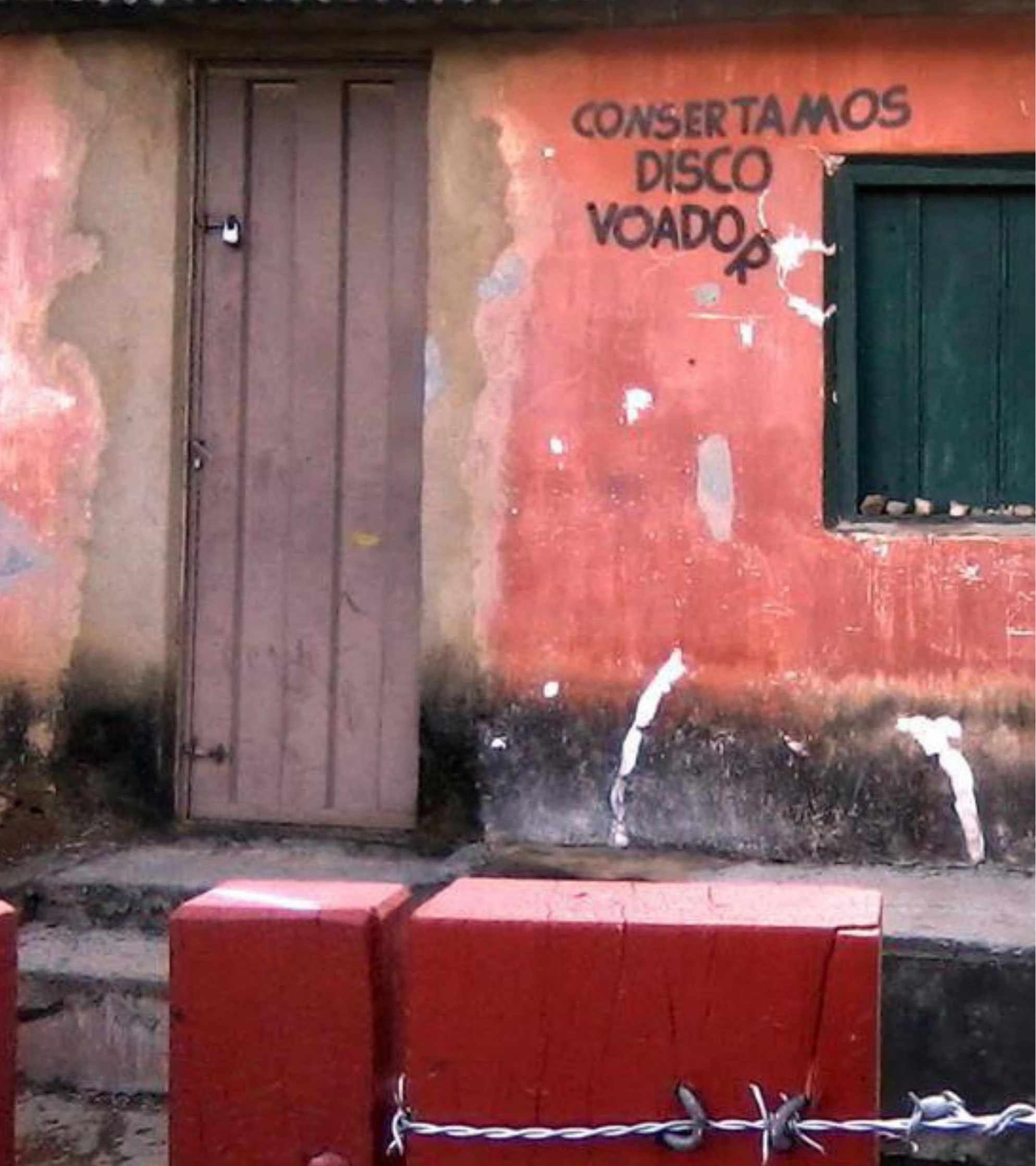


\title{
Reflexões sobre a elaboração de projetos de Geoparque a partir da perspectiva do território e do turismo
}

Reflections on the development of Geopark projects from the territory and tourism perspectives

\author{
Vinícius Weitzel Novaes ${ }^{1}$ \\ Luiz Carlos Spiller Pena²
}

1 Graduado em turismo pela Universidade Federal de Ouro Preto (UFOP), mestrando do Programa de Mestrado Profissional em Turismo, Universidade de Brasília, Brasília, Distrito Federal, Brasil. Email: viniciuswnovaes@gmail.com

2 Doutor na área Saneamento e Ambiente pela Universidade Estadual de Campinas (UNICAMP), docente do Programa de Mestrado Profissional em Turismo, Universidade de Brasília, Brasília, Distrito Federal, Brasil. Email: spilena@unb.br 


\title{
Resumo
}

O presente trabalho analisa as propostas de implantação de Geoparques a partir da dinâmica das dimensões de território, suas práticas de poder e seu uso. A pesquisa alicerçou-se em revisão bibliográfica, literatura específica e documentos oficiais que permitissem um nível de profundidade descritivo sobre o tema. Após a exposição do referencial teórico, percebe-se que o conhecimento biofísico do território por si só não é suficiente para verificar a viabilidade de um geoparque nem de concretizar os ideais preconizados pela UNESCO, que partem do princípio de que o geoparque deve garantir participação e empoderamento popular com sua concepção, baseando-se no geoturismo e na geoeducação.

Palavras Chave: Turismo, Território, Geoparque, Geoturismo, Geoeducação.

\begin{abstract}
This paper analyzes the implantation's proposals of Geoparks from the dynamic of the territory's dimensions, their practices of power and its use. The research was based on literature review and official documents that allowed a level of a depth descriptive about the subject. After the exposure of the theoretical framework, it is noticed that the biophysical knowledge of the territory by itself is not enough to check out the viability of a geopark neither to realize the ideals advocated by UNESCO, departing from an ideia which the geopark must ensure participation and popular empowerment with its creation, basing on geotourism and geoeducation.
\end{abstract}

Keywords: Tourism, Territory, Geopark, Geotourism, Geoeducation.

\section{INTRODUÇÃO}

No mundo ocidental a noção de território está quase sempre associada à ideia de divisão, de arranjos concretos demarcados por coordenadas geográficas que precisam limites físicos. Nesse sentido, pode-se afirmar que o território congrega a base física dos Estados Nação incluindo, como no caso do Brasil, sua área continental estendida ao mar territorial, ao espaço aéreo sobrejacente e também ao seu leito e subsolo.

Tal demarcação, entendida a partir dos diferentes contextos históricos que fizeram surgir os Estados Nação remete também à noção de fronteira. Se concretamente a ultrapassamos evidenciam-se contrastes entre as diferentes formas de uso de um para outro território. Num sentido amplo, as fronteiras delimitam exercícios de soberania orientados principalmente pelos aspectos políticos, econômicos e de segurança que regem esses territórios. 
Por outro lado, a noção de território, quando associada aos espaços de vivência e convivência em sociedade, que o "delimita" a partir da construção de diferentes formas de uso culturalmente estabelecidas, permite compreender que antes de uma base territorial concreta e seus instrumentos normativos existe as maneiras diversas como seus habitantes o "delimitam". Nesse sentido, sobre o territórios se constroem diferentes territorialidades, noção assim definida por Abagli (2004).

O conceito de territorialidade refere-se, então, às relações entre um individuo ou grupo social e seu meio de referência, manifestando-se nas várias escalas geográficas - uma localidade, uma região ou país - e expressando um sentimento de pertencimento e um modo de agir no âmbito de dado espaço geográfico. No nível individual, territorialidade refere-se ao espaço pessoal imediato que em muitos contextos culturais é considerado um espaço inviolável. Em nível coletivo, a territorialidade torna-se também um meio de regular as interações sociais e reforçar a identidade do grupo ou comunidade (ALBAGLI, 2004, p. 28).

A noção de territorialidade está, portanto, além de uma dimensão estática como àquela que concebe o território nos seus limites físicos. Todavia, o território como um dado espaço geográfico concreto não se dissocia das dinâmicas sociais que, mesmo na diversidade de interesses, o configuram como um território de interesse comum.

[...] a partir do espaço geográfico, cria-se uma solidariedade orgâni$\mathrm{ca}$, o conjunto sendo formado pela existência comum dos agentes exercendo-se sobre um território comum. A sobrevivência, não importa que os diversos agentes tenham interesses diferentes, depende desse exercício da solidariedade indispensável ao trabalho e que gera visibilidade do interesse comum (SANTOS, 2000, p. p.109-110).

Para Albagli (2004, p. 23-62), o território e a territorialidade podem ser considerados sob as mesmas quatro dimensões de Souza (1995), porém sob diferentes perspectivas: 1) dimensão física - são as características físicas especificas de cada território como clima, vegetação, solo independente se forem naturais ou decorrentes das práticas humanas no local. Os elementos físicos de um território se tornam potencialidades na medida em que as sociedades se apropriam dos recursos e os transformam de alguma forma como o represamento de rios para obtenção de energia ou, inclusive, a transformação de um geositio em um Geoparque, e sua consequente exploração turística; 2) dimensão político organizacional - explicitada nas formas e dinâmicas de poder realizadas no território sejam aquelas presentes nos instrumentos normativos sejam as práticas informais, assim como nas marcas de identidade territorial como seu nome que o torna único e fortalece o sentimento de pertencimento; 3) dimensão simbólica - o território possui um patrimônio ideológico que atua no sentido da manutenção da estrutura território/identidade/mito/ 
legitimação política. Possui símbolos que permitem a identificação das pessoas como pertencentes, mesmo que de maneira arcaica, a um grupo de certa forma homogêneo. Dentre os símbolos mais característicos destacam-se a bandeira, o hino, as unidades linguísticas oficiais. São esses símbolos identitários que, muitas vezes, justificam as instituições e relações de poder instituídas. Existe grande diversidade cultural dentro de um mesmo território (considerando-se sua dimensão física), porém, não cabendo ao território em si a produção e desenvolvimento da cultura e sim ser um dos elementos constitutivos da mesma, mas não é fator determinante. Descendentes de Europeus, por exemplo, trouxeram para o Brasil, um país tropical, diversos hábitos de uma cultura típica de países frios e nórdicos; 4) dimensão econômica - fatores produtivos e dinâmica econômica estão, há muitos anos, ligados intrinsecamente ao território e a busca por novos ambientes. Desde o século XV, o período das grandes navegações foi marcado pela procura de territórios que fossem fornecedores de matérias-primas e, outros, os seus consumidores. Posteriormente, como fornecedores e consumidores, como foi caso das colônias da América Latina e, posteriormente com os processos de neocolonialismo na África. Atualmente, o uso do território continua a ser determinante na atividade econômica. A globalização e a expansão das empresas multinacionais fez com que a produção se deslocasse para onde os fatores produtivos fossem mais favoráveis ao capital, onde o valor da alienação da mão de obra fosse facilitasse a produção de maior lucro para as indústrias. Ressalte-se que a força dessa dimensão muitas vezes sobrepuja ou mesmo subjuga os diferentes aspectos contidos nas três primeiras quando, de maneira ideal, a consideração da diversidade de interesses contida em cada uma delas representaria o exercício da solidariedade indispensável ao trabalho que geraria uma visibilidade de interesses em comum no uso do território (Santos, 2000).

A partir da reflexão acima, o presente artigo pretendeu desenvolver uma abordagem crítica acerca da importância de que os aspectos dessas diferentes dimensões do território estejam contemplados nas propostas de elaboração de Geoparques, em especial aqueles que possuam o seu foco de criação igualmente centrados na promoção do Geoturismo. Considerando, ainda, que no Brasil tais proposições são prerrogativa da Companhia de Pesquisas em Recursos Minerais - CPRM, constituídas a partir de um corpo técnico qualificado na área geológica.

O artigo envolveu reflexões acerca das noções de território e territorialidade a partir das quais se pretendeu estabelecer um contraponto com o conhecimento da noção de patrimônio geológico, no Brasil, e as possibilidades postas a partir do que se entende e pratica como Geoconservação e suas práticas correlatas como a do Geoturismo. Assim, se um Geoparque será implementado qual seria a ideia de 
território que sustenta a sua proposta de criação, inclusive para a prática do Geoturismo? Um Geoparque para a prática do Geoturismo materializaria um conjunto de interesses em comum no uso do território? De forma que, ao menos a partir das suas premissas os seus objetivos demonstrassem uma sinergia próxima à ideia de um solidariedade orgânica no uso a que se proporia.

A metodologia na construção da presente reflexão baseou-se em revisão bibliográfica, em literatura específica e em documentos oficiais que permitissem um nível de profundidade descritivo porém não menos importante ao exercício de construção de um artigo científico.

\section{TERRITÓRIO E PODER}

O ideário envolto no termo território demanda, como assinalado na introdução, reflexões adstritas ao exercício do poder, haja vista que, tradicionalmente, o território é o espaço em que o Estado exerce suas atividades. Moraes (2005) afirma que os territórios são entidades históricas, que expressam o controle social do espaço por uma dominação política institucionalizada.

No processo da redemocratização brasileiro o papel do próprio Estado foi flexibilizado, tendo em vista a abertura democrática e de revisão da Constituição Federal onde novos elementos emergem possibilitando novas formações territoriais, constituídas a partir da percepção de que o espaço passa a ser um instrumento político, ao passo que é apropriado e transformado em território (LEFEBVRE, 1976, apud RÜCKERT, 2005).

Tal perspectiva posta na prática abriu possibilidades para a (re) organização do território que, a partir da complexidade de tais mudanças, demandou igualmente outras maneiras de interpretação. Conforme Haesbaert (2005), à noção elementar de território surgiram conceitos que auxiliaram no aprofundamento da sua comprensão.

Desterritorialização ou regionalização parte da premissa de que território e região são conceitos indissociáveis. Para tanto, quando se fala em regionalização, se fala de construção e destruição de regiões, de forma indissociável à construção, destruição e reconstrução de territórios.

A multiterritorialidade é um fenômeno da pós-modernidade e está relacionada a perspectiva da interligação, em rede, de espaços contínuos. Desta forma, os espaços se articulam e inter-relacionam-se em rede, de modo a constituírem territórios, fortalecendo não apenas fragmentos em uma determinada área, mas também a ideia de território como algo múltiplo, e não como algo fragmentado a partir da 
tradicional concepção de regionalização (destruição, separação, fragmentação).

Essa multiterritorialidade permite que se pense numa reterritorialização, em que os territórios articulados se alinhem, em função não só de questões topográficas, mas também de questões imateriais, já que territorialização pode ser concebida como

Práticas e significados humanos em relação ao espaço, ou seja, suas formas de apropriação e dominação, nos termos de Lefebvre (1984), sem relação ou um tipo de controle, seja ele de caráter mais material ou mais simbólico, sobre o contexto espacial no qual está inserido, o homem sendo também um homo geographicus (SACK, 1996), em cada momento da história e em cada contexto geográfico revela sua própria forma de des-territorialização. (HAESBAERT, 2005, p. 20).

A reterritorialização contemporânea é complexa, e se contrapõe a regionalização tradicional, resultado da divisão estática de áreas de um território maior, ou fragmentação deste território em territórios menores (zonas), em recortes coerentes, realizada a partir da simples identificação de regiões a partir de dados geofísicos ou topográficos em comum. É o desdobramento de um complexo processo de percepção de alinhamento de contextos regionais.

Nesse sentido, o Estado brasileiro, fundamentado na democracia, deve respeitar as diversas formas de organização territorial do povo, notadamente as de comunidades tradicionais, por exemplo. Assim, sempre que haja qualquer atuação, ou qualquer intervenção sobre determinada área, deve respeitar as diversas organizações territoriais, sob pena de descaracterizar os hábitos culturais historicamente construídos de determinada comunidade, que pode depender desta área para manutenção de seus hábitos - descaracterizando, por fim, a construção democrática do território que emerge de um Estado democrático.

Para Raffesttin (1993), ao se refletir sobre a questão do território e seu uso deve-se ter em conta que "o território se forma a partir do espaço". Indo além, que tal uso representa "o resultado de uma ação conduzida por um ator sintagmático (ator que realiza um programa) em qualquer nível. Ao se apropriar de um espaço, concreta ou abstratamente (...), o ator 'territorializa' o espaço".

A partir dos conceitos de desterritorialização e reterritorialização percebe-se que uma abordagem sobre território constitui-se de forma muito mais ampla e complexa, para além do físico ou biológico, para um nível imaterial e simbólico, composto de forma cultural, por seres com capacidade de representações sociais que transformam o meio em que se inserem. Destacando-se que para a concepção destas representações sociais há interferências de variáveis econômicas, de gênero, etárias, étnicas, religiosas, entre outras. Apreende-se, portanto, que as atuais considera- 
ções sobre o território e sua formação, em uma orientação de um país democrático, estão intrinsecamente permeadas pela identidade dos grupos que os compõe.

\section{PATRIMÔNIO GEOLÓGICO NO BRASIL E GEOCONSERVAÇÃO}

A reflexão realizada sobre território, no sentido de que este não consiste apenas no patrimônio físico, mas que possui múltiplas dimensões, e de que o espaço se torna território a partir da ação dos atores sociais que nele se inserem, consiste o fundamento da abordagem realizada em relação aos geoparques - aplicando-se, inclusive, às demais unidades de conservação.

Desta forma, as percepções relacionadas aos projetos de elaboração de geoparques devem partir da premissa de que cultura, historicidade e identidades de um povo compõem o território, construído democraticamente. Essas considerações, ainda que iniciais, são suficientes para definir qual é a concepção de território a ser adotada ao se pensar a inserção de geoparques sobre o território.

Para além dessa percepção, ou seja, indo além dos referenciais teóricos sobre as concepções basilares à discussão sobre projetos de geoparques - não esgotados nas considerações iniciais - existem os marcos normativos e políticos que norteiam as práticas relacionadas a elaboração e implementação das respectivas propostas.

Iniciando pelo inciso VII do artigo $4^{\circ}$ da Lei do Sistema Nacional de Unidades de Conservação (SNUC) - Lei n. 9.985, de 18 de julho de 2000 - que inclui a proteção do patrimônio geológico e geomorfológico dentre as suas diretrizes.

Art. 4o O SNUC tem os seguintes objetivos:

VII - proteger as características relevantes de natureza geológica, geomorfológica, espeleológica, arqueológica, paleontológica e cultural; (BRASIL, 2000).

Percebe-se que a legislação considera a existência desse patrimônio com ênfase preservacionista, mas que, apesar disso, o tesouro geológico brasileiro muitas vezes é desconhecido ou desconsiderado, em que pese a ausência de previsão de criação de geoparques pela lei do SNUC (BRASIL, 2000).

No Brasil, o relevo se destaca na paisagem, proporcionando cenários exuberantes e mirantes que permitem a contemplação de áreas pouco conhecidas. Na constituição do relevo, destacam-se as serras, os picos, as chapadas e afloramentos de rochas, como por exemplos as chapadas Diamantina (na Bahia), dos Veadeiros (em Goiás), dos Guimarães (em Mato Grosso); Pão de Açúcar (no Rio de Janeiro); picos vulcânicos do Cabugi (no Rio Grande do Norte) e de Nova Iguaçu (no Rio de Janei- 
ro); Cataratas do Iguaçu (no Paraná); Cabo de Santo Agostinho (em Pernambuco); dentre outros. Todos esses diferentes tipos de relevo são formados por rochas sedimentares, ígneas e metamórficas. Esses locais são excelentes para a criação de sítios geológicos-geomorfológicos, hoje muito utilizados para a prática do turismo de aventura por meio de atividades como o traking, happel, offroad e outras (NASCIMENTO, AZEVEDO, MANTESSO NETO, 2007).

Assim, a partir do patrimônio geomorfológico emerge o conceito de geodiversidade, compreendido como

O estudo da Natureza abiótica (meio físico) constituída por uma variedade de ambientes, composição, fenômenos e processos geológicos que dão origem às paisagens, rochas, minerais, águas, fósseis, solos, clima e outros depósitos superficiais que proporcionam o desenvolvimento da vida na Terra, tendo como valores intrínsecos a cultura, o estético, o econômico, o científico, o educativo e o turístico (s/p) (CPRM, 2006).

No contexto da preservação insere-se a geoconservação, que apesar de incluída na Lei que institui o Sistema Nacional de Unidades de Conservação da Natureza (art.4으, inciso VII, Lei SNUC), não apresenta fortes movimentos visando exclusivamente a preservação do patrimônio geomorfológico. O que se observa é que muitas vezes esse patrimônio está presente em outras áreas de preservação, e por isso também estão protegidos.

A ocorrência de valores geológicos enquadrados em áreas protegidas, frequentemente, é uma mera coincidência. No Brasil, os fenômenos geológicos têm sido protegidos de forma casual, entre os valores biológicos, estéticos e culturais, em vez de serem por seus próprios valores científicos (Ruchkys, 2007, p. 11).

A ausência de uma orientação nesse sentido levou o Departamento Nacional de Produção Mineral - DNPM, em meados da década de 1990, a criar um grupo de trabalho instituído como Comissão Brasileira dos Sítios Geológicos e Paleobiológicos - SIGEP. Grupo que envolveu inicialmente a participação de várias instituições interessadas: Academia Brasileira de Ciências-ABC; Associação Brasileira para Estudos do Quaternário-ABEQUA; Departamento Nacional de Produção Mineral-DNPM; Instituto Brasileiro de Geografia e Estatística - IBGE; Instituto Brasileiro do Meio Ambiente e dos Recursos Naturais Renováveis-IBAMA; Instituto do Patrimônio Histórico e Artístico Nacional-IPHAN; Petróleo Brasileiro SA - Petrobras; Serviço Geológico do Brasil-CPRM; Sociedade Brasileira de Espeleologia-SBE; Sociedade Brasileira de Geologia-SBG; Sociedade Brasileira de Paleontologia-SBP. Diante disso, a SIGEP começou a ter como função principal o gerenciamento de um banco de dados nacional de geossítios, bem como a sua disponibilização para o público em geral em 
inglês e português na internet. Além disso, publicou dois livros contendo informações sobre mais de 50 geossitios brasileiros de interesse preservacionista. 3

A partir desse interesse, sedimentou-se a noção de geoconservação, um dos elementos para a implementação e manutenção dos geoparques, como será observado. Entretanto, por se tratar de um elemento novo no meio acadêmico, não há um consenso sobre a sua definição. Para Sharples (2002, p. 81):

(...) a preservação da diversidade natural (ou geodiversidade) de significativos aspectos e processos geológicos (substrato), geomorfológicos (paisagem) e do solo, mantendo a evolução natural (velocidade e intensidade) desses aspectos e processos.

Brilha (2005) traz de forma clara o conceito de geoconservação, diferenciando-o e comparando-o com outros conceitos correlacionados. Para ele, antes de qualquer definição é importante salientar que o patrimônio geológico engloba patrimônio paleontológico, o patrimônio mineralógico, o patrimônio geomorfológico, o patrimônio petrológico e o patrimônio hidrogeológico. Na mesma obra o autor caminha de uma perspectiva macro para uma micro e define Geossítio, patrimônio geológico e Geoconservação:

Geossitio - ocorrência de um ou mais elementos da geodiversidade (afloramentos quer em resultados da acção de processos naturais quer devido à intervenção humana), bem delimitado geograficamente e que apresente valor singular do ponto de vista cientifico.

Patrimônio Geológico - é definido pelo conjunto de Geossitios inventariados e caracterizados numa dada região.

Geoconservação - tem como objectivo a conservação e gestão do Patrimônio Geológico e processos naturais a ele associados. (Brilha, 2005, p. 190)

Com essa visão de preservação do patrimônio geológico, em 1989/90 a Organização das Nações Unidas para Educação, Ciência e Cultura - UNESCO, junto com a União Internacional para a Conservação da Natureza (International Union for the Conservation of Nature - IUCN) e a União Internacional das Ciências Geológicas (International Union of Geological Sciences - IUGS) iniciou uma listagem com sítios geológicos ao redor do mundo e de valor universal denominada Lista Indicativa Global de Sítios Geológicos (Global Indicative List of Geological Sites ou GILGES), substituída em 1996 pela Global Geosites da IUGS (Database on Geological Sites) objetivando criar uma base de dados global de sítios geológicos.

3 (http://sigep.cprm.gov.br) Acesso em 18/07/2015 


\section{GEOPARQUES}

A partir das premissas do patrimônio geológico e da geoconservação, em 2004 foi criada pela UNESCO a Rede Global de Geoparques Nacionais (RGGN), com sede em Pequim. A UNESCO define Geoparque como

[...] um território de limites bem definidos com uma área suficientemente grande para servir de apoio ao desenvolvimento socioeconômico local. Deve abranger um determinado número de sítios geológicos de relevo ou um mosaico de entidades geológicas de especial importância científica, raridade e beleza, que seja representativa de uma região e da sua história geológica, eventos e processos. Poderá possuir não só significado geológico, mas também ao nível da ecologia, arqueologia, história e cultura (UNESCO, 2004).

A noção de Geoparque aparece como uma alternativa que corrobora não apenas à conservação do patrimônio geológico, mas sua divulgação e utilização como elemento gerador de atividade de visitação turística:

A criação de Geoparques pode constituir um importante instrumento na concretização do desenvolvimento sustentável. Um geoparque é uma área em que se conjuga a Geoconservação e o desenvolvimento econômico sustentável das populações que a habitam. Procura-se estimular a criação de atividades econômicas suportadas na geodiversidade da região, com o envolvimento empenhado nas comunidades locais.

Nos finais dos anos 90, a Divisão de Ciências da Terra da UNESCO promoveu a criação do programa geoparque no seio daquela organização, como resposta ao reconhecimento crescente da necessidade de conservação do Patrimônio Geológico (Eder, 1999). Para a UNESCO, um geoparque é um território com limites bem definidos e com uma área suficientemente alargada de modo a permitir um desenvolvimento sócio econômico local, cultural e ambientalmente sustentável. O Geoparque deverá contar com geossitios de especial relevância cientifica ou estética, de ocorrência rara, associados a valores arqueológicos, ecológicos, históricos ou culturais (BRILHA, 2005, p.121).

Atualmente, no Brasil, as propostas de elaboração de Geoparques, a exceção do Geoparque do Araripe, criado em 2006, como o primeiro Geoparque das Américas, durante a 2nd UNESCO Conference on Geoparks, que se realizou em Belfast, Irlanda do Norte, são realizadas pela Companhia de Pesquisas em Recursos Minerais CPRM, por um corpo técnico qualificado na área geológica.

No mesmo ano de criação do Geoparque do Arapripe, a CPRM criou o Projeto Geoparques, que tem como escopo a identificação, levantamento, descrição, inventário, diagnóstico e ampla divulgação de áreas com potencial para futuros geoparques no território nacional. 
O Projeto estabelece algumas regras, alinhadas as regras da UNESCO, para identificação de áreas com potencial para o Geoparque. Deve, por exemplo, incluir vários sítios em um roteiro para visitação demonstrando sua importância no desenvolvimento da estrutura da Terra tal qual se conhece, ou mesmo explorando a beleza do local em conjunto som seus biomas e a importância geológica para constituição dos mesmos. A CPRM já definiu várias áreas, em quase todos os Estados Brasileiros com levantamentos que indicam, a possibilidade de desenvolvimento de Geoparques. Mesmo assim, ainda aponta que mais áreas ainda são passiveis de serem inseridas no Projeto.

Todavia, destaca-se que tais propostas de Geoparques foram elaboradas a partir conhecimento técnico estritamente associado ao patrimônio geológico, partindo-se da premissa do território a partir da paisagem e do patrimônio geofísico, e concebendo-o como elemento suficiente para a implementação de um Geoparque. Depreende-se que, num segundo plano, permaneceriam as atividades correlatas como as de turismo.

Sendo assim, é necessário que os projetos sejam elaborados a partir de uma abordagem mais ampla sobre a noção de território, onde figure a sua interrelação com o fenômeno turístico. Sob esse ponto de vista, o fenômeno do turismo depende também do território para se configurar, para se construir não somente como uma atividade sobre o território, mas a partir dele. Segundo Steinberger (2009 p.33):

\begin{abstract}
O turismo, antes de ser um fenômeno, um sistema, uma prática, um produto, um serviço ou uma indústria, é um uso do território. A anterioridade está no pressuposto de que o turismo só pode ser objeto de uma análise dialética, funcionalista, fenomenológica, sistêmica, neo-positivista, empírica ou operacional porque é um uso do território. Se esse uso não se efetivar, não há turismo e, assim não há o que analisar. Além disso, essa efetivação só existe a partir do turista como sujeito que empreende um deslocamento para um território determinado.
\end{abstract}

\title{
3.1 Geoturismo e Geoeducação
}

Para que um geoparque atinja seus objetivos é preciso que sejam desenvolvidas atividades relacionadas ao Geoturismo e à Geoeducação, e não somente à Geoconservação. Ademais, a Geoeducação, a Geoconservação e o Geoturismo devem ser desenvolvidos considerando a noção de que os usos do território pressupõem sua construção num viés solidário, do interesse comum, sob pena de manutenção de propostas de Geoparques verticalizadas. 
Em relação ao Geoturismo, em que pesem os questionamentos sobre sua constituição como segmento do turismo, o conceito surgiu muito mais para enfatizar a necessidade de preservação dos sítios geológicos. Recentemente Ruchkys (2007, p.211) definiu o Geoturismo como sendo:

[...] um segmento da atividade turística que tem o patrimônio geológico como seu principal atrativo e busca sua proteção por meio da conservação de seus recursos e da sensibilização do turista, utilizando, para isto, a interpretação deste patrimônio tornado acessível ao público leigo, além de promover a sua divulgação e o desenvolvimento das ciências da Terra.

Dessa forma, o Geoturismo seria um segmento turístico alinhado ao ecoturismo enquanto prática com fundamento na sustentabilidade, uma vez que consiste em atividade turística com responsabilidade ambiental, que busca interpretar e compreender os processos geológicos inseridos na caracterização de determinada paisagem.

Ante a percepção da geodiversidade, e da divulgação de uma identidade única para cada lugar, a atividade geoturística apresenta-se como importante vetor para a conservação e sustentabilidade locais, inclusive por ações de cunho pedagógico, focadas na preservação do patrimônio geológico (NASCIMENTO, RUCHKYS, MANTESSO-NETO, 2007).

Isso posto, a atividade geoturística contribuiria para uma ação contrária àquela que contribui para a perda de qualidade ambiental e desgaste da paisagem dos destinos turísticos. Insere-se no contexto de manutenção, para gerações futuras, dos elementos abióticos que marcam a história evolutiva da Terra - da geodiversidade em sentido amplo. Dessa forma, as atividades geoturísticas compõem-se em atividades de Geoconservação e atividades de Geoeducação, que, de forma articulada, propiciam uma experiência turística para além das fronteiras visitação contemplativa.

A Geoeducação também se insere dentro de uma perspectiva em que os geoparques devem fomentar a divulgação de conhecimento sobre determinada fase do passado e evolução da Terra e que permitiram certa formação geológica, concebendo-se a geodiversidade como herança coletiva, no intuito de decodificar a paisagem que se apresenta ao visitante, garantindo uma interpretação mais científica sobre ela (BENTO e RODRIGUES, 2010).

A interpretação e compreensão da paisagem propiciada pela Geoeducação desencadeia a Geoconservação, uma vez que as atividades turístico-pedagógicas em questão partem das premissas da sustentabilidade e necessidade de conservação do patrimônio geológico. 
Tendo as práticas geoeducativas como marco para o desenvolvimento do turismo no âmbito dos Geoparques, viabilizar-se-ia a inserção da comunidade, na qualidade de conhecedores da realidade do território - e constituintes do mesmo, o que pode estabelecer um importante vetor de desenvolvimento econômico sustentável, construído sobre a participação e utilização consciente dos habitantes locais sobre a Geodiversidade.

Ressalta-se que referidas práticas educativas e fomentadoras do desenvolvimento econômico sustentável, também tem como alicerce estratégico a educação ambiental, no sentido de qual modelo educativo merece ser discutido quando da implementação de um Geoparque.

A política pública nacional de educação ambiental, apesar de em constante possibilidade de (re)discussão, foi instituída pela Lei 9795/1999, que predispõe que:

Entendem-se por educação ambiental os processos por meio dos quais o indivíduo e a coletividade constroem valores sociais, conhecimentos, habilidades, atitudes e competências voltadas para a conservação do meio ambiente, bem de uso comum do povo, essencial à sadia qualidade de vida e sua sustentabilidade (e é objetivo da educação ambiental o) incentivo à participação individual e coletiva, permanente e responsável, na preservação do equilíbrio do meio ambiente, entendendo-se a defesa da qualidade ambiental como um valor inseparável do exercício da cidadania. (BRASIL, 1999)

Percebe-se, portanto, que não é só o território que deve ser construído de forma democrática e participativa; no caso dos Geoparques, o território em que são implementados deve partir também dessa premissa, bem como as práticas educativo-ambientais, elemento chave para que se afirme a existência de um geoparque, ao lado dos elementos da Geodiversidade e Geoconservação.

\subsection{Geoeducação e empoderamento}

A noção de uma construção solidária do território como fator de sobrevivência do mesmo (SANTOS, 2000) relaciona-se ainda a um outro fator determinante na convergência dos diferentes interesses que sobre o mesmo ascendem.

Sugere-se nesse sentido que a noção de empoderamento, verbete recorrente quando se pensa em movimentos sociais, em democracia participativa e práticas emancipatórias (como a educação), pode ser útil a partir do seu significado enquanto "capacidade do indivíduo realizar, por si mesmo, as mudanças necessárias para evoluir e se fortalecer" (BAQUERO, 2012). Esse sentido encontra um olhar importante, a ser considerado, quando na construção da proposta de um Geoparque existe o risco da exclusão de agentes inseridos no território. Romano (2002) afirma que 
o empoderamento é "(...) um processo pelo qual as pessoas, as organizações, as comunidades assumem o controle de seus próprios assuntos, de sua própria vida e tomam consciência da sua habilidade para produzir, criar e gerir".

Wallerstein \& Bernstein (1994) diferenciam o empoderamento individual do comunitário. Consideram o empoderamento individual, também denominado psicológico, a capacidade de tomar decisões para gerir a própria vida, com significado de autotutela. Já o empoderamento social é considerado como aquele em que sujeitos e organizações utilizam suas capacidades visando um objetivo comum. Possui alcance maior capaz de produzir alterações sociais. As ações presumem compartilhamento de recursos. [tradução nossa]

A educação, considerada como um processo de aquisição de conhecimento que gera um pensamento crítico e emancipatório em relação ao mundo tem papel fundamental no processo de empoderamento. Adorno (1995, p. 151) define como processo de emancipação pela educação

(...) aquilo que caracteriza propriamente a consciência é o pensar em relação à realidade, ao conteúdo - a relação entre as formas e estruturas de pensamento do sujeito e aquilo que este não é. Este sentido mais profundo de consciência ou faculdade de pensar não é apenas o desenvolvimento lógico formal, mas ele corresponde literalmente à capacidade de fazer experiências. Eu diria que pensar é o mesmo que fazer experiências intelectuais. Nesta medida e nos termos que procuramos expor, a educação para a experiência é idêntica à educação para a emancipação.

Seguindo esse pensamento, percebe-se que a educação e a informação constituem elementos basilares para tomadas de decisão, e, portanto, consistem em elementos-chave para a plena participação social (ROSO; ROMANINI, 1994)

Nesse sentido, a Geoeducação assume papel fundamental na Geoconservação e, igualmente, no empoderamento, no sentido de que a amplitude da participação dos interesses diversos possibilita, em tese, uma transformação da realidade de vida dos agentes inseridos em um território.

Um agente local as se apropriar do conhecimento sobre as formas geológicas presentes em seu território, da importância daquele geossítio para o conhecimento da história do planeta, e dos danos irreversíveis advindos com sua destruição, passa a fazer parte de um processo de construção e difusão do conhecimento, conferindo à transformação social não apenas as possibilidades do desenvolvimento econômico que propiciariam atividades relacionadas ao Geoturismo, mas também a construção de uma formação de sua cidadania. Esse conhecimento que empodera permite 
a intervenção e questionamento consciente e seguro sobre a formulação mesma das políticas públicas socioeconômicas e ambientais que considerarem implantar sobre os territórios projetos de Geoparques e Geoturismo.

\section{CONSIDERAÇÕES FINAIS}

Observa-se que território não é um conceito determinado apenas por elementos físicos, como relevo, flora e fauna, mas é composto por elementos sociais, culturais, econômicos e históricos, e por isso está em permanente (re)construção, a partir da participação de seus habitantes.

Dessa forma, a elaboração de propostas como as de um Geoparque, assim como sua implementação, dependem não somente de estudos técnicos e levantamentos desenvolvidos por geólogos, mas de uma análise que compreenda todas as áreas do conhecimento que convergem para o território, para que assim se permita a ampliação do entendimento sobre a dinâmica territorial em torno de um determinado sitio eleito, inserindo também o conhecimento da sociedade na elaboração de projetos de Geoparques, conjugando até mesmo a lógica da preservação ao desenvolvimento econômico através do turismo, conforme proposto pela UNESCO (2004).

Dessa forma, a Geoconservação, a educação ambiental e o empoderamento da população local, incentivado no processo de elaboração para a criação de Geoparques, também podem ter papel propulsor de fortalecimento de territorialidades, de (re) construção e sentimento de pertencimento ao território, compreendido no sentido mais complexo como colocado no início desse artigo. Sem esquecer que as diversas possibilidades de Geoparques em território nacional (muitos em regiões periféricas, como no nordeste e norte do país) apresentam possibilidades e perspectivas do Geoturismo como importante vetor de crescimento e emancipação cidadã.

Para tanto, a implementação de determinado Geoparque deverá partir de práticas efetivamente inclusivas, sobretudo as práticas pedagógicas inseridas no contexto da Geoeducação e Geoconservação. Caso contrário, os objetivos que pressupõem como sustentáveis para a sociedade (UNESCO, 2004) não passarão de postulados cristalizados em documentos oficiais. É imprescindível que, desde o primeiro momento, a sociedade civil organizada tenha voz nas deliberações relacionadas à formulação de propostas de Geoparque.

Destaca-se, por fim, que elaboradas de forma verticalizada, as propostas de criação de Geoparques tendem a repelir as possibilidades de construção participativa no e do território em que será inserido, contraditório à ação de um estado democrático. 


\section{REFERÊNCIAS}

ADORNO, Theodor Wiesengrund. Educação e Emancipação. In: ADORNO, Theodor Wiesengrund. Educação e Emancipação. Tradução de Wolfgang Leo Maar. Rio de Janeiro: Paz e Terra, 1995.

ALBAGLI, Sarita. Território e territorialidade In: LAGES, Vinícius; BRAGA, Christiano Lima; MORELLI, Gustavo. (Org.). Territórios em movimento: cultura e identidade como estratégias de inserção competitiva. Rio de Janeiro: Relume Dumará, 2004, p. 23-64.

BAQUERO, Rute Vivian Angelo. Empoderamento: instrumento de emancipação social? uma discussão conceitual. Revista Debates. Porto Alegre, v. 6, n. 1, p.173-187, abr. 2012.

BENTO, Lilian Carla Moreira; RODRIGUES, Silvio Carlos. O Geoturismo como instrumento em prol da divulgação, valorização e conservação do patrimônio natural abiótico - uma reflexão teórica. Revista Pesquisas em turismo e Paisagens Cársticas, Campinas-SP, v.2, n.3, p. 55-65, 2010.

BRASIL. MINISTÉRIO DO DESENVOLVIMENTO AGRÁRIO.SECRETARIA DE DESENVOLVIMENTO TERRITORIAL. Plano Territorial de Desenvolvimento Rural Sustentável do Sertão do Araripe. Brasília: 2006.

. Lei n. 9.795, de 27 de abril de 1999. Dispõe sobre a educação ambiental, institui a Política Nacional de Educação Ambiental e dá outras providências.

. Lei n. 9.985, de 18 de julho de 2000. Regulamenta o art. 225, § 10, incisos I,

II, III e VII da Constituição Federal, institui o Sistema Nacional de Unidades de Conservação da Natureza e dá outras providências.

BRILHA, José Bernardo Rodrigues. Património Geológico e Geoconservação: A Conservação da Natureza na sua vertente Geológica. Editora Palimage, Portugal, 2005.

HAESBAERT, Rogério. Desterritorialização, Multiterritorialidade e Regionalização. In: Para pensar uma política nacional de ordenamento territorial: anais da Oficina sobre a Política Nacional de Ordenamento Territorial, Brasília, 13-14 de novembro de 2003/Ministério da Integração Nacional, Secretaria de Políticas de Desenvolvimento Regional (SDR). - Brasília, MI, 2005.

MORAES, Antônio Carlos Robert. Ordenamento Territorial: uma conceituação para o planejamento estratégico. In: Para pensar uma política nacional de ordenamento territorial: anais da Oficina sobre a Política Nacional de Ordenamento Territorial, Brasília, 13-14 de novembro de 2003/Ministério da Integração Nacional, Secretaria de Políticas de Desenvolvimento Regional (SDR). - Brasília, MI, 2005.

NASCIMENTO, Marcos Antônio Leite; AZEVEDO, Úrsula Ruchkys; MANTESSO 
NETO, Virgínio. Geoturismo: um novo segmento de Turismo no Brasil. Periódico de Turismo.v.03, n. 02, nov/2007.

RAFFESTIN, Claude. Por uma geografia do poder. São Paulo: Ática, 1993.

ROMANO, Jorge O. Empoderamento: recuperando a questão do poder no combate à pobreza. In: ROMANO, Jorge O.; ANTUNES, Marta. Empoderamento e direitos no combate à pobreza. Rio de Janeiro: ActionAid Brasil, 2002. 116 p.

ROSO, Adriane; ROMANINI, Moises. Empoderamento individual, empoderamento comunitário e conscientização: um ensaio teórico. Psicologia e Saber Social, Rio de Janeiro, v. 3, n. 1, p.83-95, jul. 2014.

RUCHKYS, Ursula de Azevedo. Patrimônio geológico e geoconservação no Quadrilátero Ferrífero, Minas Gerais: potencial para a criação de um geoparque da UNESCO. Tese (Doutorado em Geologia), Instituto de Geociências da UFMG. 2007.

RUCKERT, Aldomar Arnaldo. O processo de reforma do Estado e a Política Nacional de Ordenamento Territorial. In: Para pensar uma política nacional de ordenamento territorial: anais da Oficina sobre a Política Nacional de Ordenamento Territorial, Brasília, 13-14 de novembro de 2003/Ministério da Integração Nacional, Secretaria de Políticas de Desenvolvimento Regional (SDR). - Brasília, MI, 2005.

SANTOS, Milton. Por uma outra Globalização: do pensamento único à consciência universal. Rio de Janeiro / São Paulo: Record, 2000

SHARPLES, Chris. Concepts and principles of geoconservation. Publicado eletronicamente no site da Tasmanian Parks \& Wildlife Service. 3. ed. Set, 2002

SOUZA, Marcelo J.L. O território sobre espeaço e poder, autonomia e desenvolvimento. In: Castro, Iná E.; Gomes, Paulo C.C. e Correa, Roberto L. (orgs.). Geografia: conceitos e temas. Rio de Janeiro: Bertrand Brasil, 1995.

STEINBERGER, Marília. 2009. Turismo, território usado e cidade: uma discussão pré-teórica. In: STEINBERGER, Marília. (Org.). Territórios turísticos no Brasil Central. Brasília: LGE. pp. 29-55.

UNESCO. World Geopark. 2004. Disponível em:<www.worldgeopark.org $>$. Acesso em março de 2015.

WALLERSTEIN, Nina \& BERNSTEIN, Edward. "Introduction to Community Emporwerment, Participation, Education, and Health". In: Health Education Quarterly: Special Issue Community Emporwerment, Participatory Education, and Health - Part I. Vol 21, 2: 141-170. 